\title{
viewpoint
}

\section{Bioethicsin China}

\author{
Although national guidelines are in place, their implementation remains difficult \\ WolfgengHennig
}

$\mathrm{T}$ he history of bioethics in China is a rather short one: attention was first given to research and medical ethics in the 1960s. Courses on biomedical bioethics became obligatory in the 1980s. In 1983, Qiu Xiangxing first published the textbook Medical Ethics for Chinese colleges (Q iu, 2005), which was subsequently used for teaching medical students. The Chinese Association for Medical Ethics was also founded in the mid-1980s, and the Ministry of Public Health released its first guidelines on medical ethics; however, these guidelines were not legally binding regulations. In 1998, the Ministry of Health issued a provisional document which defined the procedures for ethical reviews of any biomedical research involving humans in China. In detail, it regulates topics such as informed consent, the responsibilities of investigators, the rights of research subjects, and the administrative management of ethical reviews and legal responsibilities. In its introductory section, the document states that ethical reviews are "based upon the principles of ethics accepted by the international community".

\section{... Chinese regulations and guidelines do not substantially differ from those in Europe or the USA ...}

Today, the Ministry of Health's national Biomedical Research Ethics Committee manages and oversees all biomedical research ethics in China. In addition, local authorities in the provinces and autonomous regions must establish their own committees to review research proposals that touch on ethical questions. Their interaction with the national committee is on the basis of 'professional guidance' rather than on hierarchical frameworks. Research and health institutions in the provinces submit all research projects that require ethical review to their local committee, which then accepts or rejects the project.

\section{M any}

hospitals, research insti-

tutes and universities

have also set up their own bioethical review committees to screen applications before submitting them to the local authorities.

The regulation of bioethical issues in China is complemented by documents describing 'Good Clinical Practice', in accordance with internationally recognized principles. The documentation explicitly refers to the Declaration of Helsinki (WMA, 2004) as the basis for research involving humans, and to the International Ethical Guidelines for Biomedical Research involving Human Subjects from the Council for International Organizations of Medical Sciences (Geneva, Switzerland; CIOMS,
2002). These regulations of biomedical research, clinical trials and clinical treatments are under the control of the State Drug Administration, and include instructions on protocol design, organization, conducting, monitoring, auditing, recording, analysing and reporting. However, a major shortcoming of the documents is that they contain little detailed instructions for investigators.

The present legal and regulatory situation concerning the ethical aspects of biomedical research shows that the

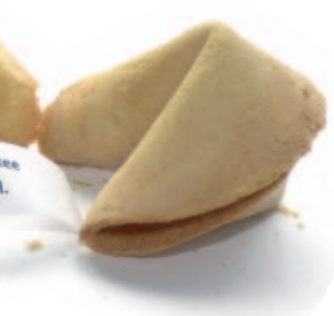

Chinese regulations and guidelines do not substantially differ from those in Europe or the USA; however, in contrast to European and US regulations, they are not enforceable by law. The question then arises as to what extent they are implemented. Such an evaluation must consider whether local committees are sufficiently skilled to perform their tasks and how these requirements are handled in daily practice. Here I try to summarize my insight into both aspects, on the basis of discussions with Chinese colleagues and on information available from official documents and public resources, particularly China Daily and Shanghai Daily-two English-language, government-controlled newspapers for foreigners. 
$\mathrm{t}$ is difficult to determine to what extent research and health institutions throughout the country have established their own ethical review committees. Reasonably, one can assume that all major research institutes, medical universities and highranking hospitals that perform biomedical research have established internal committees. The Chinese Academy of Sciences' Shanghai Institute for Biological Sciences, for example, set up a commission several years ago which has 15 members, including professionals from biology, medicine, ethics, social sciences and philosophy. All research proposals with bioethical considerations must be approved by this committee before they are submitted to the local authorities for assessment.

\section{.. theimplementation of Chinese regulationsand guidelines in daily research and clinical practiceisnot comparablewith Western standards}

From discussions with friends and colleagues, I have gained the impression that these institutional committees do not always perform sufficiently well, mainly owing to their limited experience in handling ethically relevant questions. This is, of course, a problem not only in China but also for similar committees in other countries; indeed, it requires a considerable background knowledge and experience in various fields to discuss the ethical implications of biomedical research.

Earlier this year, I realized how difficult it can be to make such ethical decisions. I chaired one of four discussion groups at the 7th G lobal Forum on Bioethics in Research in Developing Countries in Karachi, Pakistan, which debated a situation that occurred during last year's earthquake in Pakistan. The Pakistani government was not prepared to purchase enough vaccine to prevent the outbreak of typhus and a possible epidemic in the affected regions. Nevertheless, half of the required amount of typhoid vaccine was made available by a private donor, who also suggested carrying out a study to assess whether a limited vaccination campaign would be sufficient to prevent an outbreak. The discussion groups came to quite different judgements: the majority of participants considered such a study unethical and even suggested refusing the vaccine. My own group, after critical discussion of the facts, considered it sensible to make use of the available vaccine to protect at least a part of the population and, if possible from an organizational point of view, to use this opportunity to gather research evidence which could provide guidance for similar cases in the future. Although this might appear to be an exceptional example, it highlights the fact that many members of ethical review committees-in China and elsewhere-do not have sufficient experience to deal with such problems. Decisions will therefore depend on the composition and the personalities of members in the respective committees as well as on their previous experiences.

Although it is safe to assume that most research proposals with bioethical implications undergo ethical review in major research and medical institutions, the implementation of $C$ hinese regulations and guidelines in daily research and clinical practice is not comparable with Western standards. Again, the main problem is that scientists and medical staff are not properly trained, not only in terms of understanding the ethical principles related to their work, but also-and especially for medical staff- in communicating with patients.

This latter aspect is particularly critical as the general level of education in large parts of the Chinese population is rather low. Consequently, it is a difficult or almost impossible task to guarantee that patients understand all the relevant details of their treatment or the research in a meeting with medical staff or researchers. Moreover, many medical doctors-and even more researchers-do not have sufficient training in dealing appropriately with the interests of patients. This is further compounded by cultural problems in China, which make it difficult to explain and discuss sensitive topics openly with a patient; in fact, this is often more easily communicated to relatives. I have also seen cases in which medical information was given to people unrelated to the patient. Such a practice infringes on the idea of informed consent- which can only be given by the individual concerned-and is in conflict with patients' rights of privacy.

There is little information available on how informed consent for treatment or research trials is obtained in China (Cyranosky, 2005a). Most physicians in the majority of hospitals, and medical

\section{Another major problem is corruption, which neglects even themost basic of patients' rights}

staff outside main cities and in rural regions, do not have sufficient background knowledge and education to inform their subject properly according to international rules or national Chinese regulations. In rural regions, medical treatment is often carried out by people who have few or no qualifications, such as local public health workers.

Another problem-specific to Chinais the reluctance of patients to donate tissue samples or blood for biomedical research. Throughout Chinese history, the population has often been misinformed about the true intentions of the ruling powers so that they have developed a general mistrust towards politicians that extends to include scientists. O ne can therefore safely conclude that the daily practice in most Chinese research and medical institutions is not in accordance with basic ethical principles and existing bioethical regulations. It will require substantial efforts to train scientific and medical personnel at all levels to ensure that they adhere to internationally recognized standards when dealing with patients or research subjects.

$\mathrm{T}$ he difficulties are not restricted to the level of education of research and medical staff. Another major problem is corruption, which neglects even the most basic of patients' rights. The Shanghai Daily recently exposed an example of how corruption impairs medical treatment, on the basis of information provided by Xinhua, the official Chinese News Agency (Xinhua, 2006). The company Pukang Biotech in Zhejiang illegally marketed a hepatitis vaccine without approval by the governmental health services to a private dealer who sold the vaccine at a price of CNY25, although the market price was CNY6. The Dazhuan Town Hospital, in the Anhui province, used the vaccine to immunize children in 19 schools. Of more than 2,500 vaccinated children, 311 fell ill and one died as a result of the poor quality of the vaccine (Shanghai Daily, 2005). Obviously, several people-both private individuals and public officials-profited from this action. The responsibility rests not only with the private dealer but also with 
local authorities and hospital staff-four officials were punished by the Communist Party of China and several hospital employees were imprisoned for 18 months to 2 years (Shanghai Daily, 2006). This incident shows that China is still a long way from establishing functional controls in its public health system, in particular-but not exclusively-in more remote regions of the country (Xinhua, 2006).

$\mathrm{L}$ ast year, $\mathrm{N}$ ature reported another case in which governmental controls and regulations were probably ignored by both medical staff and local authorities (Cyranoski, 2005b). Hongyun Huang, a Beijing neural surgeon, treats patients with spinal-cord injuries or various neurodegenerative diseases by transplanting fetal brain tissue to the spinal cord. The publication of his method has been rejected by several international scientific journals on the basis of the argument that the data do not meet international safety standards and that necessary controls are lacking-a conclusion that has recently been supported by three internationally recognized neurologists (Dobkin et al, 2006).

\section{China is still a long way from establishing functional controls in its public health system, in particular - but not exclusively - in more remote regions of thecountry}

Huang reported in 2004 that he had successfully treated more than 500 patients without side effects. H owever, D obkin et al (2006) contradicts this statement by showing that five out of seven patients who underwent Huang's method experienced complications that were not caused by poor surgical practice. Paul Lu, a Chinese neurologist at the University of California, San Diego, USA, has for a long time tried to publish a critical evaluation of Huang's treatment in Chinese medical journals and newspapers, to warn patients that the surgery might be a waste of money-if not worse. H is translation of D obkin et al's article has now been accepted for publication in the Chinese Journal of Spine and Spinal Cord. Lu argues that Chinese "journals like to claim that China is leading the world in cell transplants" and they "Iose face if they print" his article (Cyranoski, 2006a).

\section{Chinese scientists are becoming aware of the difficulties of validating research results... and the risk of morescientific misconduct being discovered has raised serious concerns}

Of interest in this context is the controversial view of the local ethics committee in the Chaoyang Hospital in Beijing, which has approved the surgery. This decision disregarded governmental regulations and also, probably unintentionally, contradicted the opinion of international experts in neurology. According to the regulations of the $M$ inistry of Health, issued in 1998, the following "research and associated activities" are forbidden: "the use of human embryonic and fetal tissues from abortion or miscarriage, with the exception of placenta from natural birth, in research and development of products". As Huang uses tissue from aborted fetuses for his surgery, it seems either that these regulations have been modified or that medical treatment does not fall under these regulations; however, it is most likely that the governmental regulations have simply been ignored.

The Huang case reveals several problems. First, the extent and quality of controls in his surgery simply do not meet international medical standards. Second, the precise position of the ethics committee on Huang's method is unknown, as no information exists in the literature. However, a third, more fundamental problem, is the position of domestic medical journals, which is clearly dictated by traditional Chinese attitudes. The Chaoyang Hospital's ethics committee might have found it difficult to reach a conclusion about Huang's controversial treatment for similar reasons. O ne could respect such a position in another context, but it is hardly compatible with international standards in science and international agreements on bioethical issues.

In my opinion, Huang's neural surgery highlights a range of ethical, cultural, regulatory and scientific problems for ethics committees in general. There is an urgent need for these committees to obtain further experiences in order to apply the official regulations efficiently. Another problem is that the responsibilities for regulating research, and the decisions of ethical review committees, are divided between the Ministry of Public Health and the Ministry of
Science and Technology. Better coordination between these agencies, or even concentrating the responsibilities into one of them, might be useful.

The Huang case also draws attention to the regulations of China's Drug Administration on Good Clinical Practice. As pointed out before, both the Declaration of Helsinki and the CIOMS guidelines provide the basis for Chinese regulations that define the procedure and the responsibilities in clinical trials. Chinese regulations request, among other things, "control or open, parallel or crossover, double-blind or single-blind, randomization methods", "efficacy assessment", and recording of "adverse events and reporting methods for serious events". Huang's methodology must also be evaluated in light of these rules. The recent investigation of side effects (Dobkin et al, 2006) indeed leaves questions as to what extent the rules of good clinical practice have been followed.

T he scientific misconduct committed by Hwang Woo Suk in South Koreawho faked research on cloned human stem-cell lines (Cyranoski, 2006b,c)-has found much resonance in China, particularly as similar events have recently come to light. In a widely covered case, Chen Jin, a Chinese computer scientist, claimed to have developed a new sophisticated signal processing computer chip. In May this year, however, it was revealed that Chen had faked his research and stolen chip designs from a foreign company (Barboza, 2006). Earlier this year, two professors from the Life Science and Technology Institute of Tongji University in Shanghai and from the medical school of Qinghua University in Beijing were dismissed because of scientific misconduct (China Daily, 2006). This might not be the only case, as Chinese graduate and postgraduate students, as well as scientists in higher positions, are under pressure to produce publications in order to obtain their degrees or financial support for their work (Cho, 2002; Jia, 2006). The Chinese Academy of Sciences required two firstauthor publications to obtain a PhD and only recently lowered this requirement to one first-author publication. As a consequence of the pressure to publish and to produce tangible results, the quality of research might be affected (Xin, 2006). In early June, the Chinese M inistry of Science and Technology announced reforms with the aim to discourage and uncover scientific misconduct 
(Yidong \& Xin, 2006). In January this year, the Ministry had already published such measures in its Recommendations on Reforming Management of Science and Technology Programs. Chinese scientists are becoming aware of the difficulties of validating research results (Li, 2003), and the risk of more scientific misconduct being discovered has raised serious concerns, which will lead to research being more strictly controlled and supervised (Jia, 2006; Yu, 2006).

$O$ ften, the question has been raised as to whether Chinese scientists might pursue human reproductive cloning. Such concerns were first triggered by work from collaboration between Chinese and US researchers, in which zygotes with different mitochondrial complements were unsuccessfully implanted into a womb (Zhang et al, 2003). O n closer inspection, this work violates Chinese rules on human cloning and is definitely not allowed under US or European law; such experiments are no longer conducted. With regard to human reproductive cloning, the regulations of the M inistry of Health clearly state that "scientific research related to human asexual reproduction (cloning reproduction)... [is] forbidden." In 2004, the M inistry of Science and Technology also issued regulations for research with human embryonic stem cells, which explicitly ban reproductive cloning of humans.

\section{... foreign research could easily escape controlsin China by taking advantage of the undeveloped structure of medical services in rural regions}

By contrast, regulations from the M inistry of Health and the Ministry of Science and Technology allow human therapeutic cloning. These rules control how human embryonic stem cells are obtained for research and how blastocysts are cultivated after nuclear transfer while prohibiting their insertion into a reproductive system with the aim of creating embryos. The combination of human gametes with those from other species is also forbidden. However, in China there are no public concerns about cloning of any kind and therefore no real obstacles to further developments in this field of research. Cloning of animals has been established in a number of Chinese laboratories (M a \& Schmid, 2003), and the expertise is clearly available. However, a general lack of cooperation "within and outside China" hampers efficient development and even leads to "unethical and unfair competition" (Yang, 2004). Increased attention and scrutiny is required to guarantee the implementation of governmental rules and regulations (Cho, 2002; D öring, 2003).

$\mathrm{T}$ he Ministry of H ealth's documents regulating bioethical issues also refer to research in the context of "international cooperation or introduced from abroad". Chinese companies or individuals who want to conduct biomedical research involving humans abroad must first obtain approval by the Ministry of Health's Ethics Committee and by the National Health Administration. The same is true for foreign companies or individuals who plan to conduct such research in China: they need permission both from their own countries' authorities and from the appropriate Chinese institutions before the research is started. How ever, the insertion of human oocytes after somatic nuclear transfer into a woman's womb has violated these regulations (Zhang et al, 2003; Pearson, 2003), and certainly violated fundamental ethical rules (Lawler, 2002). Li (2003) stated in an article in China Daily, "We must be aware that some scientists from developed countries make use of the ignorance and eagerness of their colleagues in the developing countries to carry out experiments banned in their own nations." At present, foreign research could easily escape controls in China by taking advantage of the undeveloped structure of medical services in rural regions. It will therefore be an important task, not only for Chinese authorities but also for other countries, to implement appropriate laws and controls to prevent activities that would violate Chinese regulations and the laws of other nations.

At present, the standards of clinical trials in China are lower than international standards and might not be accepted by authorities in other countries (Jia, 2005); foreign companies conducting such trials in China therefore risk practical and legal consequences. Under its 6th Framework Programme, the European Commission has therefore established BIONET, a consortium that deals with bioethical issues in the interactions between Europe and China. Its task is to summarize events and discussions on the ethical aspects of research in European-Asian collaborations during the next three years. The ultimate aims are to guarantee that European companies conducting biomedical research in China follow fundamental rules of bioethics, and to develop clear guidelines for research cooperation that meet both Chinese and European laws.

$\mathrm{n}$ conclusion, bioethical issues in China are well covered by various national guidelines and regulations, which are clearly defined and adhere to internationally recognized standards. However, the implementation of these rules remains difficult, because they provide only limited detailed instructions for investigators. This is further compounded by the shortage in appropriately trained research and healthcare personnel, the low education level of many patients and the difficulties in controlling the application of these regulations, especially in rural regions. The Chinese government therefore faces a major task in enhancing the awareness of scientists and medical staff in China that the rights of individuals include aspects of bioethics and that this is closely linked to human rights in general, as has been documented by the UNESCO Universal Declaration on Bioethics and Human Rights (UNESCO, 2005; Wolinsky, 2006).

\section{REFEREN CES}

Barboza D (2006) In a computer scientist's fall, China feels robbed of glory. N ew York Times, 15 May, pA1

China Daily (2006) Top scientist lambastes scientific misconduct. China Daily, 2 Jun

Cho P (2002) Human Embryonic Stem Cell Research in China. Beijing, China: US Embassy. www.usembassy-china.org.cn/sandt/stemcell.htm

CIO M S (2002) International Ethical Guidelines for Biomedical Research Involving H uman Subjects. Geneva, Switzerland: Council for International O rganizations of M edical Sciences

Cyranoski D (2005a) Consenting adults? N ot necessarily... N ature 435: 138-139

Cyranoski D (2005b) Fetal-cell therapy: paper chase. Nature 437: 810-811

Cyranoski D (2006a) Patients warned about unproven spinal surgery. Nature 440: 850-851

Cyranoski D (2006b) Your cheatin' heart. $N$ at Med 12: 490

Cyranoski D (2006c)Verdict: Hwang's human stem cells were all fakes. N ature 439: 122-123

Dobkin BH, Curt A, Guest] (2006) Cellular transplants in China: observational study from the largest human experiment in chronic spinal cord injury. Neurorehabil N eural Repair 20: 5-13

Döring 0 (2003) China's struggle for practical regulations in medical ethics. $N$ at Rev G enet 4: 233-239

Jia H (2005) China beckons to clinical trial sponsors. N at Biotechnol 23: 768 
Jia $\mathrm{H}$ (2006) Fighting against fabrications in China's academia. China Daily, 29 Apr Lawler A (2002) U S questions H arvard research in China. Science 296: 28

Li X (2003) Ethics needed in medical research. China Daily, $310 \mathrm{ct}$

Ma L, Schmid RD (2003) Chinese Bio Today. Shanghai, China: Printing Center of the General O ffice of the CPC Shanghai M unicipal Committee

Pearson H (2003) Human fertility experiment promptswrath. News@N ature, 13 Oct

Q iu X (2005) M edical Ethics, 2nd edn. Beijing, China: People's M edical Publishing House

Shanghai Daily (2005) Inoculation illness toll hits 215. Shanghai Daily, 28 Jun

Shanghai Daily (2006) Four officials published in case of tainted vaccine. Shanghai D aily, 13 Jan

UNESCO (2005) U niversal Declaration on Bioethics and H uman Rights. Paris, France: U N ESCO
W MA (2004) Declaration of Helsinki: Ethical Principles for M edical Research Involving H uman Subjects. Ferney-le-Voltaire, France: World Medical Association

Wolinsky H (2006) Bioethics for the world. EMBO Rep 7: 354-358

Xin H (2006) Scandals shake Chinese science. Science 312: 1464-1466

Xinhua (2006) Stronger control over vaccination urged for safety. Shanghai D aily, $15 \mathrm{Mar}$ Yang X (2004) An embryonic nation. N ature 428: 210-212

Yidong G, Xin H (2006) China's science ministry fires a barrage of measures at misconduct. Science 312: 1728-1729

Yu Z (2006) Code set to safeguard academic ethics. China Daily, 25 May

Zhang J, Zhuang G, Zeng Y, A costa C, Shu Y, Grifo J (2003) Pregnancy derived from human nuclear transfer. Fertil Steril $\mathbf{8 0}$ (Suppl 3): S56

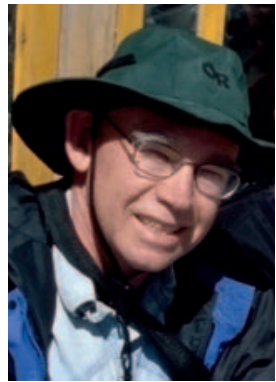

WolfgangH ennigisat the CAS-Max-Planck-Partner Institutefor Computational Biology (PICB), Shanghai Institutes for Biological Sciences, Shanghai, China.

E-mail: whennig@sibs.ac.cn

doi:10.1038/sj.embor.7400794 